\title{
Inventory of scorpion fauna (Arachnida Scorpiones) in Tiaret region (Algeria)
}

\author{
Fatma Bousmahal*, Malika Adamou-Djerbaoui' ${ }^{2}$ Fatiha Labdelli², Mohamed Essalah Azzaoui ${ }^{3}$, Fatima \\ Beldjillali², Khadidja Raci², Khadidja Titaf ${ }^{2}$ \& Walid Dahmani² \\ ${ }^{1}$ Hygienique and pathological animal Laboratory Veterinary school, IbnKhaldoun University, Tiaret, Algeria \\ 2.Faculty of Sciences of Nature and Life and Laboratory of Agro-Biotechnology and Nutrition in Semi-Arid Zone, Ibn Khal- \\ doun University of Tiaret, Algeria \\ ${ }^{3}$ Higher School of Agronomy Mostaganem, Algeria \\ *Corresponding author: fleurs_jasmin@yahoo.fr.
}

ABSTRACT

KEY WORDS

\begin{abstract}
The present work was carried out in the region of Tiaret to study the diversity of scorpions in western Algeria. In this locality, three stations were chosen: the first one is a rocky area, the second one is represented by a scrub and the third is an anthropized zone. The scorpions sampling was done, during the year 2017, randomly and it was carried out by searching the scorpions in their hiding places, where a total of 200 individuals were sampled. The specimens morphometry, based on the measurement of 8 parameters, made it possible to diagnose two families: Buthidae represented by two species Buthus occitanus (Amoreux, 1789) (88.5\%) and Buthacus arenicola (Simon, 1885) (7\%) and Scorpionidae represented by Scorpio maurus Linnaeus, 1758 (4.5\%). Among the measures that make the difference between these species, we mention the width of the chela, which is of the order of $3.03 \pm 0.67$ for Buthus occitanus and $2.27 \pm 0.49 \mathrm{~mm}$ for Buthacus arenicola, while Scorpio maurus has larger chela.
\end{abstract}

Algeria; Buthidae; Inventory; Scorpionidae; Tiaret.

Received 13.03.2019; accepted 16.05.2019; published online 18.06.2019.

\section{INTRODUCTION}

Scorpions form an order of about 600 species, all thermophiles, of which none exceeds, so northward as southward 50 degrees of latitude (Boué \& Chanton, 1974). Scorpions occur in tropical and subtropical regions and also in more moderated regions of hemispheres like in the North and the South of America. In North America they unfold far in the northern regions and in Canada (approximately $52^{\circ} \mathrm{N}$ ). In South America, scorpions occur in the south of Chile and in Argentina (approximately $50^{\circ} \mathrm{S}$ ).

Scorpions show different models of adaptation to various types of environments, even inhabited by humans. Several works were made on the scorpions. Simon (1910) made a revision of the scorpions of Egypt that were the object for a works by Vachon (1952; 1974; 1975). El Hennawy (1992) wrote a catalog of the scorpions of Arab countries. Polis (1990) noted that the diversity of the scorpions is relevant in deserts and dry regions and other contributions were made by Lourenço et al. (2002, 2003), Lourenço \& Leguin (2011), Touloun (2004), Touloun et al. (2001, 2014), Touloun \& Boumezzough (2011), and Badry et al. (2017).

For this reason, our study is an attempt to determine the inventory of the Fauna scorpions in the region of Tiaret, West Algeria. The investigation is 
done through the morphometry of these scorpions in three stations of the region of Tiaret.

\section{MATERIAL AND METHODS}

The present study uses a random sampling selection of scorpions. The scorpions collection were carried out in three stations. The first station is Mellakou, represented by a rocky naked ground and situated at a height between 943 and 1114 meters. The second station is Ledjdar, a scrubland situated at a height between 1114 and 1491 meters. The third station is Guertoufa, a mountainous and anthropized zone, situated at a height between 275 and 943 meters. The collection of the scorpions in the various stations was made by looking for the scorpions in their hiding places, under wooden branches, debris or stones.

Each scorpion was kept individually in a glass jar. The date of the collection, the site and number were mentioned on the jar. In the laboratory, several measures of morpho-metric were taken to the collected scorpions, like the total length, the length of the prosoma, mesosoma, metasoma, length of the vesicle with poison, length and width of the femur, the patella, the length of the mobile finger and others.

\section{RESULTS AND DISCUSSION}

A morphological examination of the collected scorpions was made by the keys of identification of Vachon (1952) and other similar works (Lourenço, 2006; Lourenço \& Vachon, 2004).

The scorpions found in the three Algerian stations belong to two families and three species. Family of Buthidae C.L. Koch, 1837 is represented by two species, Buthus occitanus (Amoreux, 1789) (88.5\%) and Buthacus arenicola (Simon, 1885) (7\%). The family of Scorpionidae Latreille, 1802 is represented by Scorpio maurus Linnaeus, 1758 (4.5). These results are showed in Table 1.

The results of the figure 2 allowed to draw a factorial analysis of correspondences (AFC) by using the software XLSTAT (2014).

This AFC illustrates the groupings of the scorpion fauna as well as their interactions with the stations in the study area (Fig. 1).

The examination of this graph shows two relatively heterogeneous groups in both factorial axes; the analysis of the Table 2 shows that the rate of the slowness of the axis 1 is higher than the rate of the slowness of the axis 2 which means that the projection is mainly made on the first axis.

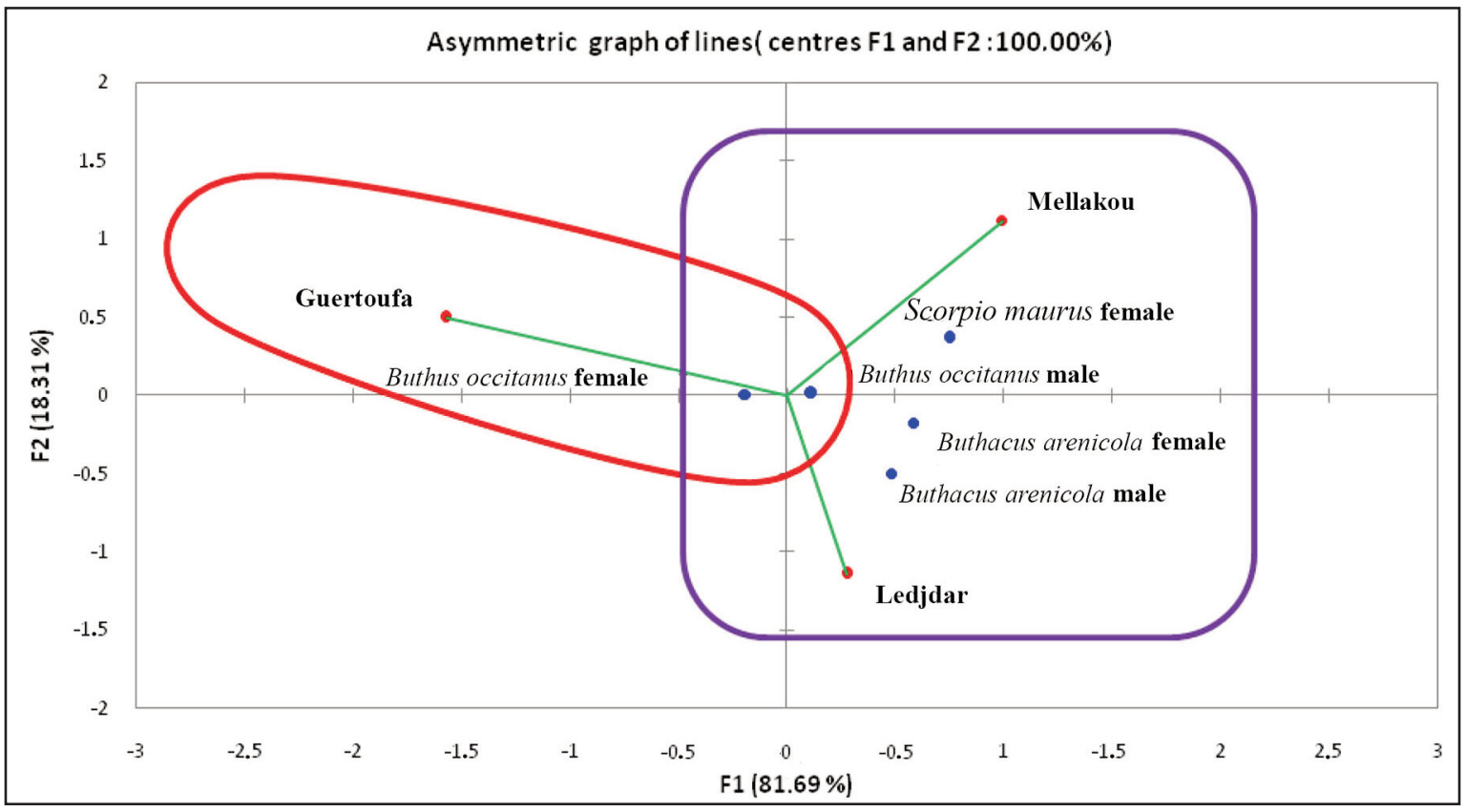

Fig. 2. Factorial Plan of stations according to species. 
According to the projection F1-F2, the axis F1 represents 81,86 of the slowness. In the same vein, we noticed that the positive side towards the extremity of the axis becomes a group in the region that includes Mellakou and Ledjdar stations with $B$. occitanus (males and females), B. arenicola (males and females) and S. maurus (females). On the negative side, at the end of the axis becomes more groups in the region that constituted the station Guertoufa with Buthus occitanus. In the center of the factorial plan, we have the formation of a bubble made up of a species met in all the stations of the study, especially Buthus occitanus (males and females).

The factorial analysis of the correspondences applied on the species captured in the region of Tiaret, allowed us to notice that B. occitanus is close to the center of the graph and in both sides, being present in the three stations of the study area.

These results are conform to the works of El Hennawy (1992) who reported for this species a large distribution in North Algeria. The two other species, $S$. maurus and $B$. arenicola, are uniquely found in two stations; the station of Mellakou and the station of Ledjdar, but are completely absent in the third station of Guertoufa (anthropized area).

\section{Morphometry and description of the invento- ried species}

Buthus occitanus. The morphometry of $B$. occitanus is illustrated in the figure 2 . The length of B. occitanus is $64 \pm 8.54 \mathrm{~mm}$. This measure gets closer to that indicated by Boué \& Chanton (1974) of $7.5 \mathrm{~cm}$ length. The length and width of femur are, respectively, $6.39 \pm 0.96 \mathrm{~mm}$ and $1.94 \pm 0.39 \mathrm{~mm}$, while of the patella are, respectively, $5.00 \pm 0.86 \mathrm{~mm}$ and $1.43 \pm 0.28 \mathrm{~mm}$. The length and the width of the chela are, respectively, of $10.64 \pm 1.54 \mathrm{~mm}$ and $3.03 \pm 0.67 \mathrm{~mm}$.

The mobile finger has length of $7.33 \pm 1.21 \mathrm{~mm}$, and the gland with poison is $6.15 \pm 0.98 \mathrm{~mm}$. The body has a yellow color, darker than the appendixes. The tail has the presence of silks. B. occitanus is the most plentiful in comparison with the other two species. In the three stations it has the rate of $88.5 \%$. This is a greater rate than the one studied by Sadine et al. (2011) in the park of Belezma in North Algeria (82.5\%).

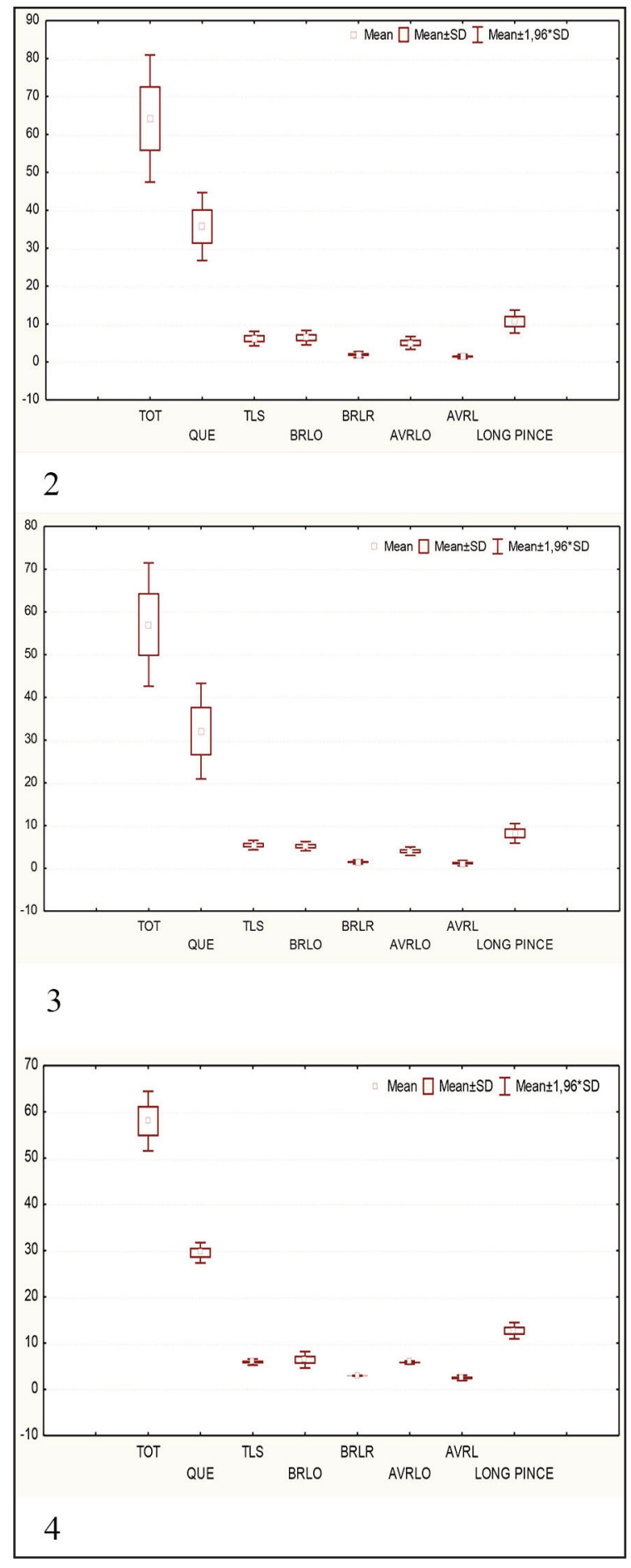

Figure 2. Morphometry of Buthus occitanus. Figure 3. Morphometry of Buthacus arenicola. Figure 4. Morphometry of Scorpio maurus. TOT: total length, TLS: length of the vesicle with poison, QUE : length of the tail, BRLO: length of the femur, BRLR: width of the femur, AVRLO: length of the patella, AVRL: width of the patella, LONG PINCE : length of the chela. 
Buthus occitanus is widespread in Africa, Asia and Europe (Lourenço \& Vachon, 2004). Lourenço (2002) mentioned that the colonization of Europe by this species was made, probably, through the coastal regions of Morocco. Lourenço \& Vachon (2004) observed that B. occitanus collected in the Sierra Nevada would be originally from the region of North Africa. Gantenbein \& Largiadèr (2003) noted that the specimens of Europe are very different from that of those found in North Africa.

Buthacus arenicola. The figure 3 shows the morphometry of $B$. arenicola. The length of this species is $57.04 \pm 7.36 \mathrm{~mm}$. The femur is long $5.18 \pm 0.54 \mathrm{~mm}$ and it is wide $1.48 \pm 0.24 \mathrm{~mm}$. The patella is long $4.00 \pm 0.50 \mathrm{~mm}$ and it is wide $1.210 .31 \mathrm{~mm}$. The length of the finger is $8.18 \pm 1.17 \mathrm{~mm}$ and it is wide $2.27 \pm 0.49 \mathrm{~mm}$. The measures of the chela found in our study are conform with the findings of Lourenço (2006) who has indicated that $B$. arenicola has a thin chela. The length of the mobile finger is $5.77 \pm 0.64$ while the length of the gland with poison is $5.44 \pm$ $0.56 \mathrm{~mm}$. The body of the specimens is brown. The tail is wide and has a dark yellow color, the vesicle with poison is smaller than that of B. occitanus and it has very thin yellow pedipalps with several silks.

This species is less common than the $B$. occitanus, and its presence was indicated only in two stations, Ledjdar and Mellakou (7 \%). According to Lourenço \& Leguin (2014), the distribution of $B$. arenicola extends from western Libya to Tunisia to northen Algeria. Vachon (1952) discussed the large distribution of the Buthacus genus and also expressed his doubts about the real taxonomic status of the various population of $B$. arenicola found in North and Northwest of Africa. Sadine et al. (2011) observed this scorpion in the region of Ouargla in South Algeria. Buthacus arenicola is present in opened spaces such as Ergs, Regs or agricultural fields of sand (Lourenço et al., 2017).

Scorpio maurus. The morphometry of the $S$. maurus is illustrated in figure 4 . The length of this species is $57.993 .28 \mathrm{~mm}$. The length and width of the femur are, respectively, $6.390 .90 \mathrm{~mm}$ and 2.94 $\pm 0.03 \mathrm{~mm}$. Those of the patella are, respectively, $5.08 \pm 0.17 \mathrm{~mm}$ and $2.470 .29 \mathrm{~mm}$. The chela is $12.67 \pm 0.89 \mathrm{~mm}$ long and it is $5.230 .64 \mathrm{~mm}$ wide. Vachon (1952) has reported that, in Algeria and Tunisia, scorpions with wide chela are always $S$. maurus. The length of mobile finger is $7.56 \pm 1.06$ $\mathrm{mm}$ while that of the gland with poison is $9.90 \pm$ $0.32 \mathrm{~mm}$. The body is dark brown with a thin tail and clearer legs. Chelicerae are striking and darkened. Pedipalps are brown, large and strong, and become more darkened in the extremities. This species is known for its capacity to live in high altitude, and it lives, normally, in the hot environments (Mozaffari et al., 2013). Fet (2000) confirmed its presence in Algeria.

Scorpio maurus is less plentiful regarding the two other species cited above, its presence rate is $4.5 \%$, and it was found in only two stations, Ledjdar and Mellakou. This rate is lower than the one registered by Sadine et al. (2011), which was 15.5 $\%$ in the park of Belezmain, North Algeria.

\section{CONCLUSIONS}

This study on the scorpions fauna, carried out in the region of Tiaret West Algeria, allowed us to

\begin{tabular}{|ccccccccc|}
\hline Stations & \multicolumn{2}{c}{ Ledjdar } & \multicolumn{2}{c}{ Mellakou } & \multicolumn{2}{c}{ Guertoufa } & Total \\
\cline { 1 - 6 } sex & Male & Female & Male & Female & Male & Female & \\
Buthus occitanus & 27 & 45 & 22 & 29 & 14 & 40 & $\mathbf{1 7 7}$ \\
Buthacus arenicola & 05 & 04 & 02 & 03 & $/$ & $/$ & $\mathbf{1 4}$ \\
Scorpio maurus & $/$ & 03 & $/$ & 06 & $/$ & $/$ & $\mathbf{0 9}$ \\
Total by sex & 32 & 52 & 24 & 38 & 14 & 40 & $\mathbf{2 0 0}$ \\
Total & & $\mathbf{8 4}$ & & $\mathbf{6 2}$ & & $\mathbf{5 4}$ & $\mathbf{2 0 0}$ \\
\hline
\end{tabular}

Table 1. Enumeration of the species inventoried by stations in Tiaret region (Algeria). 


\begin{tabular}{|lll|}
\hline & F1 & F2 \\
\hline Appropriate Values & 70 & 0.016 \\
Slowness (\%) & 81.686 & 18.314 \\
\% accumulated & 81.686 & 100.000 \\
\hline
\end{tabular}

Table 2. Appropriate Values and percentages of slowness of both axes of the AFC.

identify the Buthidae family represented by two species, B. occitanus ( $88.5 \%$ presence rate), and Buthacus arenicola $(7 \%)$ and the Scorpionidae family with the $S$. maurus (4.5\%).

The Factorial Analysis of the Correspondences (AFC) reveals that the B. occitanus is the species more common in the three stations of study area. Buthacus arenicola and S. maurus are found only in the stations of Ledjdar and Mellakou, but Scorpio maurus is less plentiful.

The morphometry of the species shows that Buthus occitanus has the chela $3.03 \pm 0.67 \mathrm{~mm}$ wide, $B$. arenicola is characterized by a thin pedipalps and chela is $2.27 \pm 0.49 \mathrm{~mm}$ wide. Scorpio maurus is characterized by its wide and strong pedipalps and with a large chela $(5.230 .64 \mathrm{~mm}$ wide).

Further studies on these faunas, carried out also in larger territories and with a greater number of stations, will be able to further improve the knowledge on this interesting group of terrestrial invertebrates.

\section{REFERENCES}

Badry A., Younes M., Sarhan M.M.H. \& Saleh M., 2017. On the scorpion fauna of Egypt, with an identification key (Arachnida: Scorpiones). Zoology in the Middle East, 64: 75-87. http://dx.doi.org/10.1080/09397140. 2017.1414976

Boué H. \& Chanton R., 1974. Zoologie, tome 1 fasc. 1: les invertebres. Doin Editors, Paris, 559 pp.

El Hennawy H.K., 1992. A catalogue of the scorpions described from the Arab countries (1758-1990) (Arachnida: Scorpionida). Serket, 2: 95-153.

Fet V., 2000. Family Scorpionidae Latreille, 1802. In: Fet V., Sissom W.D., Lowe G. \& Braunwalder M.E. (Eds), Catalog of the Scorpions of the World
(1758-1998). The NewYork Entomological Society, NewYork, 427-486 pp.

Gantenbein B. \& Largiadèr C.R., 2003. The phylogeographic importance of the Strait of Gibraltar as a geneflow barier in terrestrial arthropods. A case study with the scorpion Buthus occitanus as model organism. Molecular, Phylogenetic and Evolution, 28: 119-130.

Lourenço W.R., 2002. Considerations on the models of distribution and differentiation of the genus Buthus Leach, 1815, with the description of new species) of the mountains of Tassili of ajjer, Algeria (Scorpiones, Buthidae). Biogeographica, 78: 109-127.

Lourenço W.R., 2003. Complement in the fauna of scorpions (Arachnida) of North Africa, with considerations on the genus Buthus Leach, 1815. Revue Suisse de Zoologie, 110: 875-912.

Lourenço W.R., 2006. Further considerations on the genus Buthacus Birula, 1908 (Scorpiones, Buthidae), with a description of one new species and two new subspecies. Boletín Sociedad Entomológica Aragonesa, 38: 59-70.

Lourenço W.R. \& Leguin EA., 2011. Further considerations on the species of the genus Orthochirus Karsch,1891 from Africa, with description of three new species (Scorpiones: Buthidae). Euscorpius, 123: $1-19$.

Lourenco W.R. \& Leguin E.-A., 2014. Une nouvelle espèce d'Hottentotta Birula, 1908 pour le massif du Hoggar en Algérie (Scorpiones, Buthidae); conséquences biogéographiques sur la répartition du genre. Revista Iberica de Arachnologia, 24: 15-18.

Lourenço W.R. \& Vachon M., 2004. Considérations sur le genre Buthus Leach, 1815 en Espagne, et description de deux nouvelles espèces (Scorpiones, Buthidae). Revista Ibérica de Aracnologia, 9: 81-94.

Lourenço W.R., Sadine S. \& Bissati S., 2017. The genus Buthacus Birula, 1908 in Northern and Central Algeria; description of a new species and comments on possible micro-endemic populations (Scorpiones: Buthidae). Rivista Aracnologica Italiana, 3: 18-30.

Mozaffari E., Sedaghat M.M., Dohkordi A.S. \& Akbarzadeh K., 2013. Biodiversity and species composition of Scorpions (Arachnida, Scorpiones) in IlamConty, Iran. Journal of Applied Sciences Research, 9: 5412-5418.

Polis G.A., 1990. The Biology of Scorpions. Stanford University Press, Stanford, California, 587 pp.

Sadine S., Bissati S. \& Ould Elhadj M.D., 2011. First data on the scorpionique diversity in the region of the souf (Algeria). Arachnides, 61: 2-10.

Simon E., 1885. Études sur les Arachnides recuellis en Tunisie en 1883 et 1884 par M.M.A. Letourneux, M. Sédillot et Valéry Mayet, membres de la mission de 
l'Exploration scientifique de la Tunisie. In: Exploration scientifique de la Tunisie, Paris, pp. 1-55.

Simon E., 1910. Révision des scorpions d'Egypte. Bulletin de La Société Entomologique d'Egypte, 2: 57 87.

Vachon M., 1952. Études sur les Scorpions. Pubis Institute Pasteur Alger, $482 \mathrm{pp}$.

Vachon M., 1974. Étude des caractères utilisés pour classer les familles et les genres de Scorpions (Arachnides). 1. La tri-chobothriotaxie en Arachnologie, Sigles trichobothriaux ettypes de trichobothriotaxie chez les Scorpions. Bulletin du Muséum National d'Histoire Naturelle de Paris, (3), 140 (Zoologie 104): 857-958.

Vachon M., 1975. Etudes on the scorpions. Arm of Pédipalpes of the scorpions (arachnids) in the classification of the genus of family of Buthidae. Reports of Scéances of the Academy of Science, 28: 1597-1599.
Touloun O., 2004. Les peuplements de scorpions du sud ouest marocain: ecologie, biogéographie et Epidémiologie des envenimations. Thèse Doctorat, Faculté des Sciences Semlalia de Marrakech, Maroc, 159 pp. Touloun O. \& Boumezzough A., 2011. Une nouvelle espèce du genre Buthus Leach, 1815 (Scorpiones: Buthidae) du Maroc. Boletín de la Sociedad Entomológica Aragonesa, 48: 183-187.

Touloun O., Slimani T. \& Boumezzough A., 2001. Epidemiological survey of scorpion envenomation in Southwestern Morocco. Journal of Venomous Animals and Toxins including Tropical Diseases, 7: 199-218. http://dx.doi.org/10.1590/S0104-7930200 1000200006

Touloun O., Abdelmonaim Elhidan M. \& Boumezzough A., 2014. Inventory and distribution of scorpion fauna in eastern Morocco (Arachnida, Scorpiones). Serket, 14: 73-79. 